\title{
Adherence to the Mediterranean diet, is there any relationship with main indices of central fat in adolescent competitive swimmers?
}

\author{
Cesare Altavilla1,3, Annabelle Joulianos², José Miguel Comeche Guijarro³, Pablo Caballero Pérez ${ }^{3}$ \\ ${ }^{1}$ Foods analysis and nutrition group, University of Alicante, Spain. ${ }^{2}$ University Hospital San Juan de Alicante. ${ }^{3}$ Department of Community Nursing, Preventive Medicine, Public \\ Health and History of Science, University of Alicante, Spain.
}

doi: 10.18176/archmeddeporte.00034

Recibido: $01 / 05 / 2020$

Aceptado: 03/02/2021

Key words:

KIDMED. Body composition. Swimming. Central adiposity. Young athletes

\section{Summary}

Introduction: The relationship between adherence to the mediterranean diet and central fat of adolescent competitive swimmers is under-studied. The fat component is interesting because of its relationship to the horizontal floatation and speed during the swimming performance. An accumulation of central fat is considered a negative factor for health and performance. This study aimed to check the degree of adherence to the mediterranean diet and its relationship with some indices of central fat in competitive adolescent swimmers.

Material and method: A cross-sectional descriptive study was carried out. 74 adolescent swimmers participated in the study (males $n=34,14.5 \pm 1.3$ y.o., females $n=40,13.6 \pm 1.2$ y.o.). The swimmers completed the KIDMED questionnaire to assess their adherence to the mediterranean diet. A II level ISAK anthropometrist carried out the anthropometric data collection at the beginning of the evening swimming session.

Results: The swimmers showed a medium adherence to the mediterranean diet. Male and female swimmers showed similar KIDMED index score (males $8.09 \pm 1.5$, females $7.23 \pm 2.2$ ). Age seems to be a detrimental factor in the adherence to the mediterranean diet during adolescence. Female swimmers showed a significant lower waist/hip ratio compared to males $(-0.028 ; p=0.01)$. The adherence to the mediterranean diet was not correlated with the anthropometric measures of central fat. Conclusions: Regardless of the adherence to the mediterranean diet, elevated swimming activity maintains indices of central fat in healthy values. Despite there was no correlation between adherence to the mediterranean diet and the anthropometric measures of central fat, there are reasons related to health to improve healthy eating habits of adolescent competitive swimmers.

\section{¿Existe una relación entre la adherencia a la dieta mediterránea y los principales índices de grasa central en nadadores adolescentes de competición?}

\section{Resumen}

Introducción: La relación entre la adherencia a la dieta mediterránea y la grasa central en nadadores adolescentes está poco estudiada. La grasa es un componente interesante en natación debido a su relación con la flotabilidad horizontal y la velocidad de nado. Una acumulación de grasa a nivel abdominal se considera un factor negativo para la salud y el rendimiento deportivo. El objetivo de este estudio fue valorar el grado de adherencia a la dieta mediterránea y su relación con los principales índices de grasa central en nadadores adolescentes de competición.

Material y método: Se llevó a cabo un estudio descriptivo transversal. 74 nadadores adolescentes participaron al estudio (chicos $n=34,14,5 \pm 1,3$ años, chicas $n=40,13,6 \pm 1,2$ años). Se valoró la adherencia a la dieta mediterránea de los nadadores a través del cues-tionario KIDMED. Los nadadores fueron medidos antes de una sesión de entrenamiento vespertina. Los nadadores mostraron una adherencia moderada a la dieta mediterránea.

Resultados: Chicos y chicas mostraron puntuaciones similares (chicos $8,09 \pm 1,5$, chicas 7,23 $\pm 2,2$ ). Durante la adolescencia, a mayor edad parece empeorar la adherencia a la dieta mediterránea. Las chicas mostraron un índice cintura-cadera más bajo en comparación con los hombres $(-0,028 ; p=0,01)$. No se encontró asociación entre la adherencia a la dieta mediterránea y los principales índices de grasa central.

Palabras clave:

KIDMED. Composición corporal.

Natación. Adiposidad central.

Jóvenes deportistas.
Conclusiones: Independientemente del grado de adherencia a la dieta mediterránea, la elevada actividad natatoria mantiene los índices de grasa central en valores saludables en los nadadores adolescentes de competición. A pesar de que no encontramos asociación entre las medidas de grasa central y la adherencia a la dieta mediterránea, existen razones de salud para implementar habitos alimenticios saludables en nadadores adolescentes de competición. 


\section{Introduction}

Diet has an important role in the health, growth, performance, and recovery of swimmers. An imbalanced diet have been described in young swimmers ${ }^{1-3}$. The Mediterranean Diet (MD) has long been reported to have a large number of benefits such as the prevention of non-communicable diseases ${ }^{4}$, a lower risk of mortality ${ }^{5}$, and a lower incidence of many types of cancers $^{6}$. It could reduce central obesity and the associated chronic disease risks ${ }^{7}$. The MD is considered a healthy diet, and it is in line with general recommendations on nutrition for athletic performance. A recent review has provided data on the association between adherence to the MD and body composition? However, in adolescents, there is still an unclear correlation between adherence to the MD, physical activity, and body composition ${ }^{9-11}$. Altough, the MD can be considered one of the best studied dietary pattern in the world, the data on adolescent athletes and adherence to the MD is sparse $e^{9,12}$.

The swimmers have some "typical" anthropometric characteristics. They have long limbs and their musculoskeletal components are important in sport performance. In particular, the fat component is a paradoxical component in swimming, because of its relationship to the floatation and speed during the performance ${ }^{13}$. Previous studies have shown that the swimmers could accumulate central fat during short break from swimming activity ${ }^{14,15}$. Accumulation of central fat is an important risk factor in the development of insulin resistance, diabetes, metabolic syndrome, and cardiovascular diseases ${ }^{16,17}$. Anthropometric measures of central fat has been proposed as a great additional criteria for monitoring overweight and obesity ${ }^{18-20}$. Moreover, anthropometric measures of central fat maybe a reliable method to monitor early changes in body fat mass in adolescent swimmers ${ }^{14}$.

There is little data on adherence to the MD and adolescent swimmers ${ }^{21}$. In our knowledge, there is no studies linking the MD and anthropometric measures of central fat in adolescent competitive swimmers. The purposes of this study were: to assess the degree of adherence to the MD and its relationship with some anthropometric indices of central fat in competitive adolescent swimmers.

\section{Material and method}

\section{Participants}

A cross-sectional descriptive study was carried out. We selected 74 competitive adolescent swimmers aged between 11 and 16 y.o. from four local swimming clubs. We included swimmers with a minimum of three years of sport experience. The study was carried out in March 2017, 3 weeks after the main national and regional championships. The swimmers are semiprofessional and they usually have five or six swimming sessions per week. Normally in each session, the swimmers swam between 90 and 120 minutes (min) and covered a minimum of 3.000 meters (m). All swimmers participated voluntarily in the study and their legal guardian signed a written informed consent. The ethics committee of the University of Alicante granted ethical approval, according to the Declaration of Helsinki.

\section{Experimental design}

To assess the adherence to the MD, the swimmers completed the KIDMED questionnaire. The KIDMED questionnaire was developed by Serra-Majem et al.22 and revised to its Spanish version ${ }^{23}$. The questionnaires were provided to each participant by one or more researchers and the guidelines were explained to all participants to ensure that the questionnaire was completed appropriately. The KIDMED questionnaire is composed of sixteen questions, of which, four affirmative questions have been assigned with a negative score of -1 . While the rest have been assigned with a positive sign of +1 . The results of the KIDMED questionnaire were classified, according to the KIDMED authors, into three levels: 8-12 (high) optimal Mediterranean diet; 4-7 (medium) improvement needed to adjust intake to Mediterranean patterns; 0-3 (poor) very low diet quality 22,23 . Anthropometric data collection was carried out at the beginning of the afternoon swimming session. Participants were only wearing a swimsuit during anthropometric data collection. A II level anthropometrist accredited by the International Society for the Advancement of Kinanthropometry (ISAK) collected the measures according to the ISAK standards ${ }^{24}$. The height, waist, and hip circumference was measured with a standard flexible metallic measuring tape. Body mass was recorded using an electronic scale (Tanita BH 420MA, Tanita Corporation, Japan). Body mass index (BMI) was determined using standard equations: $\mathrm{BMI}=\left[\right.$ body mass $(\mathrm{kg}) /$ height $\left.^{2}(\mathrm{~m})\right]$. The waist/hip ratio (WHipr) was calculated as waist circumference divided by hip circumference and the waist/height ratio (WHeir) was calculated as waist circumference divided by height. To avoid subjective error, all measurements were assessed twice, and the relative mean values were used. In case of a discrepancy from 5\% to 10\% between the two measurements, a third was taken.

\section{Data analysis}

Data were grouped according to sex and age group. A group included younger swimmers (aged 11 - 13 years) and the other included older swimmers (aged 14-16 years) according to the youth swimming categories of the Royal Spanish Swimming Federation. All data are presented as mean with standard deviation (SD) and confidence intervals were calculated $(95 \% \mathrm{Cl})$. Each question of the KIDMED questionnaire was analyzed by age and sex, and the ORs and the combinations of them were calculated. Statistical analyses were performed using logistic regression adjusting for sex and age. For the latter analysis, the younger males group was the baseline. To assess the adherence to the MD a linear regression analysis was performed. A t-test was applied for differences between sexes and ages. Statistical analyses were performed using Statistical Package for the Social Sciences 18.0 software for Windows (IBM SPSS Software, Armonk, NY, USA) with statistical significance set at $p \leq 0.05$.

\section{Results}

\section{Adherence to the MD}

The swimmers showed medium adherence to the MD. The mean KIDMED score was 7.62 \pm 1.86 .2 swimmers (2.7\%) showed a poor index 
score with a very low-quality diet, 30 swimmers (40.5\%) showed medium adherence to the MD. 42 swimmers (56.8\%) showed high adherence to the MD with an optimal diet. Male and female swimmers have similar KIDMED index scores. Male swimmers showed slightly higher adherence to the MD than females, although the difference did not reach statistical significance (males $8.09 \pm 1.5 \mathrm{Cl}$ vs females $7.23 \pm 2.2 ; \mathrm{p}=0.059$ ). When sex and age statistical analysis was combined it showed that the older male swimmers (14-16 age group) have a higher index score of adherence to the MD than older female swimmers $(p=0.04)$. The older females of the 14-16 age group showed the worst adherence to the MD than the rest of the swimmers $(p=0.04)$ (Table 1). The overall results of all the questions of the KIDMED questionnaire are shown in Table 2. The majority of the swimmers consume a piece of fruit or fruit juice every day. It was revealed that only half of the swimmers consumed the second fruit daily. A small percentage of the swimmers usually go more than once a week to a fast-food (hamburger) restaurant. Male swimmers consumed more legumes per week than the female ones (question $\mathrm{n}$. $7 p<0.05$ ). The female swimmers of the $14-16$ age group consumed fewer legumes than the ones of the $11-13$ age group (question $n .7 p$ $<0.05)$. There were five females of the $14-16$ age group who usually skip breakfast (question n. 12), there were no males. Olive oil is a food usually consumed at the swimmer's home (question n. 11). The intake of cereals or grain products (question n. 9) and dairy products (question n. 13) during the breakfast were high among the adolescent swimmers. They did not consume daily sweets and candy (question n. 16) (Table 2).

\section{Measurements of the central fat}

The physical and anthropometric characteristics of the competitive adolescent swimmers are shown in Table 3. All the anthropometric measurements were within the normal range for these ages ${ }^{25,26}$. The swimmers showed healthy anthropometric values of central fat ${ }^{20,27}$. As expected there were differences in body mass and height between sexes, although BMI values were not. There also were differences in waist circumference between sexes, although there were not in hip.

There were differences in WHipr between sexes. Whereas the female swimmers showed a significant lowerWHipr compared to males $(-0.028$; Cl 95\%: $-0.05,-0.01 ; p=0.01)$. There was no correlation between WHipr and age or KIDMED score. There was no correlation between WHeir or $\mathrm{BMI}$ and sex, age or KIDMED score.

Table 1. Scores of the KIDMED questionnaire. Linear regression by age, sex and age $\mathrm{x}$ sex.

\begin{tabular}{ccccc}
\hline & $\begin{array}{c}\text { Mean (SD) } \\
\text { (IC95\%) }\end{array}$ & $\begin{array}{c}\text { Age Coef. (Sig.) } \\
\text { Cl 95\% }\end{array}$ & $\begin{array}{c}\text { Sex Coef. (Sig.) } \\
\text { Cl 95\% }\end{array}$ & $\begin{array}{c}\text { Age x Sex Coef. (Sig.) } \\
\text { Cl 95\% }\end{array}$ \\
\hline \multirow{2}{*}{ Scores } & $7.6 \pm 1.9$ & $0.16(0.78)$ & $0.20(0.74)$ & $-1.1(0.04 *)$ \\
& $(7.2,8.1)$ & $(-0.98,1.38)$ & $(-0.98,1.30)$ & $(-2.1,-0.1)$ \\
\hline
\end{tabular}

Coef. Value of the linear regression. Sig. Significance. 95\%Cl: 95\% Confidence interval, Baseline: Males between 11-13 years old; ${ }^{*} \mathrm{P}<0.05$.

Table 2. Overall results of the KIDMED Questionnaire.

\begin{tabular}{|c|c|c|c|c|c|c|c|}
\hline Questions & No (\%) & Yes (\%) & $\mathrm{OR}_{\mathrm{A}}(\mathrm{Cl} \mid 95 \%)$ & $\mathrm{OR}_{\mathrm{s}}(\mathrm{Cl} 195 \%)$ & $\mathrm{AOR}_{\mathrm{A} \mid \mathrm{S}}(\mathrm{Cl} \mid 95 \%)$ & $\mathrm{AOR}_{\mathrm{S} \mid \mathrm{A}}(\mathrm{Cl} 95 \%)$ & $\mathrm{AOR}_{\mathrm{SxA}}(\mathrm{Cl} 195 \%)$ \\
\hline 1 & 11 (14.9\%) & $63(85.1 \%)$ & $0.7(0.2-2.5)$ & $0.4(0.1-1.6)$ & $0.4(0.9-5.1)$ & $0.7(0.1-9.7)$ & $0.6(0.0-13)$ \\
\hline 2 & 32 (43.2\%) & $42(56.8 \%)$ & $0.7(0.3-1.9)$ & $0.4(0.2-1.1)$ & $1.6(0.4-6.8)$ & $0.9(0.2-3.9)$ & $0.3(0.1-0.9)^{*}$ \\
\hline 3 & 24 (32.4\%) & $50(67.6 \%)$ & $0.6(0.2-1.7)$ & $1.3(0.5-3.4)$ & $1.3(0.2-6.3)$ & $0.7(0.2-3.1)$ & $0.8(0.1-6.3)$ \\
\hline 4 & 48 (64.9\%) & $26(35.1 \%)$ & $0.7(0.3-1.8)$ & $1.2(0.5-3.3)$ & $1.8(0.4-8.0)$ & $1.1(0.2-4.9)$ & $0.4(0.1-3.3)$ \\
\hline 5 & $21(28.4 \%)$ & $53(71.6 \%)$ & $0.9(0.3-2.5)$ & $1.4(0.5-3.9)$ & $0.7(0.1-3.5)$ & $0.4(0.1-2.3)$ & $3.5(0.4-29.7)$ \\
\hline 6 & 67 (90.5\%) & 7 (9.5\%) & $1.1(0.2-5.2)$ & $0.6(0.1-2.9)$ & $1.3(0.1-6.4)$ & $2.0(0.2-21.5)$ & $0.2(0.0-7.3)$ \\
\hline 7 & $21(28.4 \%)$ & $53(71.6 \%)$ & $0.9(0.3-2.5)$ & $0.2(0.1-0.8)^{*}$ & $0.8(0.1-9.7)$ & $0.3(0.1-0.8)^{*}$ & $0.7(0.3-13.0)$ \\
\hline 8 & 36 (49.3\%) & $37(50.3 \%)$ & $0.5(0.2-1.4)$ & $1.0(0.4-2.6)$ & $0.8(0.2-3.6)$ & $0.5(0.1-1.9)$ & $1.2(0.2-8.5)$ \\
\hline 9 & $15(20.3 \%)$ & $59(79.7 \%)$ & $1.5(0.5-4.8)$ & $0.5(0.1-1.7)$ & $0.9(0.2-4.6)$ & $2.8(0.4-2.9)$ & $0.3(0.0-3.9)$ \\
\hline 10 & $23(31.9 \%)$ & 49 (68.1\%) & $0.7(0.2-2.0)$ & $0.8(0.3-2.2)$ & $0.6(0.1-3.2)$ & $0.6(0.1-2.9)$ & $1.3(0.2-10.5)$ \\
\hline 11 & $1(1.4 \%)$ & 73 (98.6\%) & (1) & ( & (1) & (1) & (1) \\
\hline 12 & 69 (93.2\%) & $5(6.8 \%)$ & $1.2(0.2-7.8)$ & (1) & (1) & (1) & (1) \\
\hline 13 & $4(5.4 \%)$ & 70 (94.6\%) & $0.4(0.4-4.0)$ & $0.4(0.4-3.8)$ & (1) & (1) & (1) \\
\hline 14 & $44(59.4 \%)$ & $30(40.5 \%)$ & $0.7(0.2-1.8)$ & $1.2(0.5-3.0)$ & $0.9(0.2-3.9)$ & $0.5(0.1-2.4)$ & $1.4(0.2-9.2)$ \\
\hline 15 & $38(51.4 \%)$ & $36(48.6 \%)$ & $2.5(1.0-6.3)$ & $0.6(0.2-1.5)$ & $2.7(0.6-13)$ & $10.7(2-54.7)$ & $0.1(0.0-0.6)$ \\
\hline 16 & 69 (93.2\%) & $5(6.8 \%)$ & $3.4(0.4-32.5)$ & $0.5(0.8-3.5)$ & ( & (1) & (1) \\
\hline
\end{tabular}

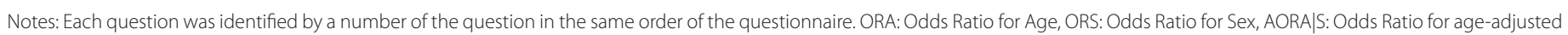

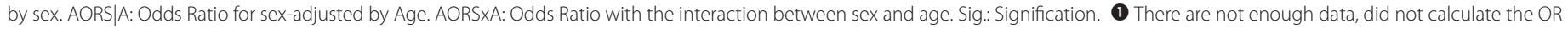
and AOR. Baseline: Males between 11-13 years old; * $P<0.05$. 
Table 3. Physical and anthropometric characteristics of the adolescent swimmers.

\begin{tabular}{lccc}
\hline & $\begin{array}{c}\text { Males } \\
\mathbf{n = 3 4}\end{array}$ & $\begin{array}{c}\text { Females } \\
\mathbf{n = 4 0}\end{array}$ & p-value \\
\hline Age (y.o.) & $14.5 \pm 1.3$ & $13.6 \pm 1.2$ & 0.03 \\
Height (cm) & $167.3 \pm 9.5$ & $158.4 \pm 5.1$ & $<0.01$ \\
Waist circumference (cm) & $69.1 \pm 5.3$ & $65.7 \pm 5.9$ & 0.01 \\
Hip circumference (cm) & $86.6 \pm 6.5$ & $85.5 \pm 7.7$ & 0.50 \\
Body Mass (kg) & $56.5 \pm 9.8$ & $50.2 \pm 8.1$ & $<0.01$ \\
Whipr & $0.80 \pm 0.04$ & $0.77 \pm 0.05$ & 0.01 \\
Wheir & $0.41 \pm 0.03$ & $0.41 \pm 0.03$ & 0.87 \\
BMl & $20.06 \pm 2.5$ & $20 \pm 2.8$ & 0.93 \\
\hline
\end{tabular}

Values are expressed as mean \pm Standard Deviation; WHipr: Waist/Hip ratio, WHeir: Waist/ Height ratio, BMl: body mass index.

\section{Discussion}

The KIDMED scores of the swimmers were not correlated with the anthropometric measurements of central fat. Greater adherence to a Mediterranean diet should lead to a lower total and central fat in children and adolescents ${ }^{8,28}$. Regardless of the degree of adherence to the $M D$, a high level of swimming would disguise the possible effects of an unhealthy or imbalanced diet. Based on our results, the adherence to the MD worsens with age. An explanation could be that older adolescents have some money to spend on food and entertainment without any parental control. The adolescent swimmers spend many hours out of the home to go to and back from the swimming training and they usually share "food time" after the swimming session. The possibility of adolescents to spend money on food out of the home does not lead to a healthy $\operatorname{diet}^{29}$, and it could increase bad eating habits with higher intake of ultra-processed food ${ }^{30}$ and sweet beverages ${ }^{31}$. Previous data regarding sex and adherence to the $M D$ in adolescents are unclear ${ }^{32,33}$. Our results showed that the female swimmers had a lower adherence to the MD than males ones. Moreover, it was observed that female swimmers had lower nutritional knowledge than male one ${ }^{34}$. We have reported that the girls consumed less fruit and legumes and there were only females who usually skip breakfast. Several studies have shown that women, especially adolescent ones, have a higher prevalence of eating disorders than men ${ }^{35,36}$. Although swimming is not considered a high-risk sport regarding eating disorders, greater attention should be given to the nutritional behavior of the swimmers, especially female ones. Almost all the swimmers consumed a piece of fruit or fruit juice daily. We have expressed some concerns about the inclusion of fruit juice in the KIDMED questionnaire ${ }^{37}$. The repeated inclusion of fruit juice in the diet may have negative effects ${ }^{31,38}$. The percentage of intake of the second piece of fruit in the second answer was lower than the percentage recorded for the first one (see Table 1). Thus, the high percentage recorded of daily intake of fruit in the first answer could be a false "cognate" biased by fruit juice intake. The number of adolescent swimmers that consumed the second piece of fruit daily is alarming. We could deduce that few swimmers consume the recommended servings of fruit per day. The current dietary guidelines have been advocating for an increase of fruit intake instead of fruit juice ${ }^{39}$. An increase of fruit intake in adolescent swimmers is strongly advisable. A possible alternative to improve the fruit intake and to substitute the fruit juice could be fruit smoothie intake. The fruit smoothie is well accepted by adolescents and it supplies water, fat, dietary fibre, vitamins, and antioxidants.

The coaches reported to us that there is no nutrition education at swimming clubs. Nutritional education appears to be an effective resource to improve Mediterranean nutritional habits in adolescent swimmers ${ }^{21}$. Targets for such education should not be limited to swimmers but also include families, schools, and coaches. Several studies have shown that the coaches had inadequate sport nutritional knowledge ${ }^{40}$. Furthermore, they often provide nutritional advice to their athletes, even though they are not competent to do $\mathrm{so}^{41}$.

Studies have reported an unclear correlation between adherence to the MD, physical activity, and BMI values 8,10,12,42. Some studies have used the body mass index (BMI) to monitor fat component ${ }^{43,44}$. Although the male and female swimmers showed differences in height and body mass, they had similar healthy BMI. Some studies have suggested that male and female swimmers could have the same BMI with different proportions of lean mass and fat mass ${ }^{45,46}$. However, the results did not show any correlation between $\mathrm{BMI}$ and the adherence to the MD. We have some concerns about BMI, mainly because it does not provide any information about the distribution of body fat. The addition of measures of central fat to BMI should be considered as greater criteria for monitoring overweight and obesity ${ }^{18-20}$. In the present study, all swimmers were semi-professional and they had a minimum of three years of sport experience. Many of them have been swimming since childhood. The results showed that the high level of swimming since childhood maintains weight and the BMI of both sexes in a healthy range.

The relationship between adherence to the MD and waist circumferences is not clear ${ }^{9,47}$. Waist circumference could reflect total body fat and fat distribution in children and adolescents ${ }^{20,48}$. Accumulation of central fat is a negative factor in swimming because central fat increases the frontal surface of the body and increases the total drag force on a swimmer. In our study, the swimmers showed a low level of fatness and healthy values of waist circumference. To have low fatness indices with healthy waist circumference values could indicate a developed kick musculature, which is the key factor for high performance in swimming. However, some anthropometric measurements of central fat could be used as early predictive measurements to assess changes in body fat at least in young swimmers ${ }^{14}$.

The female swimmers showed a significant lower WHipr than males. A low level of WHipr in women is correlated with a low risk of cardiovascular disease, diabetes, and hypertension ${ }^{49}$.

Sedentary behaviors in adolescents commonly lead to overweight and obesity. Consistent with previous studies ${ }^{50}$, our study has observed that all swimmers have healthy values in all anthropometric measurements and they did not show any accumulation of total or central fat. Thus, as expected an elevated level of swimming activity prevents the accumulation of total and central fat. Despite there was no correlation between adherence to the MD and the main indices of central fat, there are reasons related to health to im-prove healthy eating habits of adolescent swimmers. 


\section{Limitations of the study}

The cross-sectional design of the current study has some limitations. The study is a"status study" and the results are a picture indicating what is being done. The conclusions could be used as valuable indications to be taken into account for future research. The size of the sample of the study is limited. However, to our knowledge, the number of participants is higher compare to other studies. The study did not measure the relationship between the degree of adherence to the MD and some anthropometric indices of central fat with the performance in competitive adolescent swimmers.

\section{Conclusions}

There was no correlation between adherence to the MD and the main indices of central fat in competitive adolescent swimmers. Regardless of the medium adherence to the MD, the elevated swimming activity had a protective role to prevent the accumulation of central fat.

\section{Conflict of interests}

This research did not receive any grant from funding agencies in the public, commercial, or non-profit sectors. The authors have disclosed that they have no relationships with, or financial interest in, any commercial companies. Cesare Altavilla was a coach of 10 of the swimmers, who participated in the study.

\section{Bibliography}

1. Berning JR, Troup JP, VanHandel PJ, Daniels J, Daniels N. The nutritional habits of young adolescent swimmers. Int J Sport Nutr. 1991;1:240-8.

2. De Sousa EF, Da Costa THM, Nogueira JAD, Vivaldi LJ. Assessment of nutrient and water intake among adolescents from sports federations in the Federal District, Brazil. Br J Nutr. 2008;99:1275-83. doi:10.1017/S0007114507864841

3. Martínez S, Pasquarelli BN, Romaguera D, Arasa C, Tauler P, Aguiló A. Anthropometric characteristics and nutritional profile of young amateur swimmers. J Strength Cond Res. 2011;25:1126-33. doi:10.1519/JSC.0b013e3181d4d3df

4. Estruch R, Ros E, Salas-Salvadó J, Covas MI, Corella D, Arós F, et al. Primary Prevention of Cardiovascular Disease with a Mediterranean Diet. NEngl J Med. 2013;368(14):12791290. doi:10.1056/NEJMoa1200303.

5. Sofi F, Macchi C, Abbate R, Gensini GF, Casini A. Mediterranean diet and health status: an updated meta-analysis and a proposal for a literature-based adherence score. Public Health Nutr. 2014;17:2769-82. doi:10.1017/S1368980013003169

6. Schwingshackl L, Hoffmann G. Adherence to Mediterranean diet and risk of cancer: an updated systematic review and meta-analysis of observational studies. Cancer Med. 2015;4:1933-47. doi:10.1002/cam4.539

7. Bendall CL, Mayr HL, Opie RS, Bes-Rastrollo M, Itsiopoulos C, Thomas CJ. Central obesity and the Mediterranean diet: A systematic review of intervention trials. Crit Rev Food Sci Nutr. 2017:1-15. doi:10.1080/10408398.2017.1351917

8. laccarino Idelson P, Scalfi L, Valerio G. Adherence to the Mediterranean Diet in children and adolescents: A systematic review. Nutr Metab Cardiovasc Dis. 2017;27:283-99. doi:10.1016/J.NUMECD.2017.01.002

9. Galan-Lopez P, Sanchez-Oliver AJ, Pihu M, Gísladóttír T, Domínguez R, Ries F. Association between Adherence to the Mediterranean Diet and Physical Fitness with Body Composition Parameters in 1717 European Adolescents: The AdolesHealth Study. Nutrients. 2019;12:77. doi:10.3390/nu12010077

10. Zurita-Ortega F, San Román-Mata S, Chacón-Cuberos R, Castro-Sánchez M, Muros JJ. Adherence to the Mediterranean Diet Is Associated with Physical Activity, Self-Concept and Sociodemographic Factors in University Student. Nutrients. 2018;10. doi:10.3390/ nu10080966
11. Galan-Lopez P, Sánchez-Oliver AJ, Ries F, González-Jurado JA. Mediterranean Diet, Physical Fitness and Body Composition in Sevillian Adolescents: A Healthy Lifestyle. Nutrients. 2019;11:2009. doi:10.3390/nu11092009

12. Galan-Lopez P, Domínguez R, Pihu M, GísladóttirT, Sánchez-Oliver AJ, Ries F. Evaluation of physical fitness, body composition, and adherence to mediterranean diet in adolescents from Estonia:The adoleshealth study. Int J Environ Res Public Health. 2019:16(22). doi:10.3390/ijerph16224479

13. Esparza F, Cabañas MD. Compendio de Cineantropometria. (Grupo CTO, ed.). Madrid; 2009.

14. Altavilla C, Sellés-Pérez S, Comino-Comino I, Comeche-Guijarro J, Caballero-Pérez P, Tuells J. Comparisons of summer break effect on anthropometric profile, body composition and somatotype between adolescent swimmers and less active adolescents. Rev Andaluza Med del Deport. December 2019. doi:10.33155/J.RAMD.2019.12.004

15. Alméras N, Lemieux S, Bouchard C, Tremblay A. Fat Gain in Female Swimmers. Physiol Behav. 1997:61:811-7. doi:10.1016/S0031-9384(96)00559-8

16. Taylor AE, Ebrahim S, Ben-Shlomo Y, Richard M Martin, Peter HWhincup, John WYarnell, $\mathrm{S}$, et al. Comparison of the associations of body mass index and measures of central adiposity and fat mass with coronary heart disease, diabetes, and all-cause mortality: a study using data from 4 UK cohorts. Am J Clin Nutr. 2010;91(3):547-556. doi:10.3945/ ajcn.2009.28757

17. Cheong KC, Ghazali SM, Hock LK, Subenthiran S, Huey TC, Kuay Lim K, et al. The discriminative ability of waist circumference, body mass index and waist-to-hip ratio in identifying metabolic syndrome:Variations by age, sex and race. Diabetes Metab Syndr Clin Res Rev. 2015;9(2):74-78. doi:10.1016/J.DSX.2015.02.006

18. Esmaillzadeh A, Mirmiran P, Azizi F. Waist-to-hip ratio is a better screening measure for cardiovascular risk factors than other anthropometric indicators in Tehranian adult men. Int J Obes. 2004;28:1325-32. doi:10.1038/sj.ijo.0802757

19. Browning LM, Hsieh SD, Ashwell M. A systematic review of waist-to-height ratio as a screening tool for the prediction of cardiovascular disease and diabetes: could be a suitable global boundary value. Nutr Res Rev. 2010;23:247-69. doi:10.1017/ S0954422410000144

20. Schröder H, Ribas L, Koebnick C, Funtikova A, Gomez SF, Fíto M, et al. Prevalence of abdominal obesity in Spanish children and adolescents. Do we need waist circumference measurements in pediatric practice? PLoS One. 2014;9(1):e87549. doi:10.1371/ journal.pone.0087549

21. Philippou E, Middleton N, Pistos C, Andreou E, Petrou M. The impact of nutrition education on nutrition knowledge and adherence to the Mediterranean diet in adolescent competitive swimmers. J SciMed Sport. 2017;20:328-32. doi:10.1016/j.jsams.2016.08.023

22. Serra-Majem L, Ribas L, Ngo J, Ortega RM, García A, Pérez-Rodrigo C et al. Food, youth and the Mediterranean diet in Spain. Development of KIDMED, Mediterranean Diet Quality Index in children and adolescents. Public Health Nutr. 2004;7(07):931-935. doi:10.1079/PHN2004556

23. Serra L, Ribas L, Ngo J, Ortega RM, Pérez-Rodrigo C, Aranceta J. Alimentación, jóvenes y dieta mediterránea en España. Desarrollo del KIDMED, índice de calidad de la dieta mediterránea en la infancia y la adolescencia. En: Alimentación infantily juvenil. Barcelona: Masson; 2002.

24. International Standards for Anthropometric Assessment. Glasgow: The International Society for the Advancement of Kinanthropometry; 2001.

25. Alves Junior CAS, Mocellin MC, Gonçalves ECA, Silva DAS, Trindade EBSM. Anthropometric indicators as body fat discriminators in children and adolescents: A systematic review and meta-analysis. Adv Nutr. 2017;8:718-27. doi:10.3945/an.117.015446

26. Hernandez M, Castellet J, Narvaiza JL, Rincon I RE. Curvas y Tablas de Crecimiento. Madrid; 1988.

27. Taylor RW, Jones IE, Williams SM, Goulding A. Evaluation of waist circumference, waist-to-hip ratio, and the conicity index as screening tools for high trunk fat mass, as measured by dual-energy $\mathrm{X}$-ray absorptiometry, in children aged 3-19 y. Am J Clin Nutr. 2000;72:490-5. doi:10.1093/ajcn/72.2.490

28. Grosso G, Galvano F. Mediterranean diet adherence in children and adolescents in southern European countries. NFS J. 2016;3:13-9. doi:10.1016/j.nfs.2016.02.004

29. Bagordo F, Grassi T, Serio F, Idolo A, De Donno A. Dietary habits and health among university students living at or away from home in Southern Italy. J Food Nutr Res. 2013:52(3):164-71.

30. Latasa P, Louzada MLDC, Martinez Steele E, Monteiro CA. Added sugars and ultraprocessed foods in Spanish households (1990-2010). Eur J Clin Nutr. 2017;72:1404-12. doi:10.1038/s41430-017-0039-0

31. Singh GM, Micha R, Khatibzadeh S, Lim S, Ezzati M, Mozaffarian D. Estimated Global, Regional, and National Disease Burdens Related to Sugar-Sweetened Beverage Consumption in 2010. Circulation. 2015;132(8):639-666. doi:10.1161/CIRCULATIONAHA.114.010636 
32. Alexandra Bargiota, Maria Delizona, Andreas Tsitouras GNK. Eating habits and factors affecting food choice of adolescents living in rural areas. Hormones. 2013;12:246-53.

33. Alberto Grao Cruces, Antonio Fernández Martínez ANN. Association of Fitness With Life Satisfaction, Health Risk Behaviors, and Adherence to the Mediterranean Diet in Spanish Adolescents. J Strength Cond Res. 1993;28:2164-72.

34. Altavilla C, Prats-Moya MS, Caballero Pérez P. Hydration and nutrition knowledge in adolescent swimmers. Does water intake affect urine hydration markers after swimming ? Int J Appl Exerc Physiol. 2017;6:37-45. doi:https://doi.org/10.22631/ijaep.v6i4.220

35. Liechty JM, Lee M-J. Longitudinal predictors of dieting and disordered eating among young adults in the U.S. Int J Eat Disord. 2013;46:790-800. doi:10.1002/eat.22174

36. Peebles R, Bell K, Carlson J, Wilson J, Allison K, Lock J, et al. Competitive Sports, Eating Behaviors, and Menstrual Health in Female College Athletes. J Adolesc Heal. 2009; 44(2):S19-S20. doi:10.1016/j.jadohealth.2008.10.046

37. Altavilla C, Caballero-Perez P. An update of the KIDMED questionnaire, a Mediterranean Diet Quality Index in children and adolescents. Public Health Nutr. 2019;22:2543-7.

38. Martínez Steele E, Baraldi LG, Louzada ML da C, Moubarac J-C, Mozaffarian D, Monteiro CA. Ultra-processed foods and added sugars in the US diet: evidence from a nationally representative cross-sectional study. BMJ Open. 2016;6:e009892. doi:10.1136/ bmjopen-2015-009892

39. Harvard T.H. Chan School of Public Health. Healthy Eating Plate \&amp; Healthy Eating Pyramid | The Nutrition Source | Harvard T.H. Chan School of Public Health. https:// www.hsph.harvard.edu/nutritionsource/healthy-eating-plate/. Published 2011.

40. Torres-McGehee TM, Pritchett KL, Zippel D, Minton DM, Cellamare A, Sibilia M. Sports nutrition knowledge among collegiate athletes, coaches, athletic trainers, and strength and conditioning specialists. J Ath/ Train. 2012;47:205-11.

41. Cockburn E, Fortune A, Briggs M, Rumbold P. Nutritional knowledge of UK coaches. Nutrients. 2014;6:1442-53. doi:10.3390/nu6041442
42. Mistretta A, Marventano S, Antoci M, Cagnetti A, Giogianni G, Nolfo F, et al. Mediterranean diet adherence and body composition among Southern Italian adolescents. Obes Res Clin Pract. 2017;11(2):215-226. doi:10.1016/J.ORCP.2016.05.007

43. De la Montaña J, Castro L, Cobas N, Rodríguez M, Míguez M. Adherence to a mediterranean diet and its relantionship to body mass index in Galician University. Nutr clínica y dietética Hosp. 2012;32:72-80.

44. Torun NT, Yildiz Y. Assessment of Nutritional Status of $10-14$ Years Old Adolescents Using Mediterranean Diet Quality Index (kidmed). Procedia - Soc Behav Sci. 2013;106:512-8. doi:10.1016/J.SBSPRO.2013.12.057

45. Farajian P, Kavouras SA, Yannakoulia M, Sidossis LS. Dietary intake and nutritional practices of elite Greek aquatic athletes. Int J Sport Nutr Exerc Metab. 2004;14:574-85.

46. Maria N. Hassapidou, Vassiliki Valasiadou LT and PV. Nutrient intake and anthropometric characteristics of adolescent Greek swimmers. Nutr Diet. 2002;59:38-42.

47. Bacopoulou F, Landis G, Rentoumis A, Tsitsika A, Efthymiou V. Mediterranean diet decreases adolescent waist circumference. Eur J Clin Invest. 2017;47:447-55. doi:10.1111/ eci. 12760

48. Schröder H, Mendez MA, Ribas-Barba L, Covas M-I, Serra-Majem L. Mediterranean diet and waist circumference in a representative national sample of young Spaniards. Int J Pediatr Obes. 2010;5:516-9. doi:10.3109/17477161003777417

49. Li C, Engström G, Hedblad B, Calling S, Berglund G, Janzon L. Sex differences in the relationships between BMI,WHR and incidence of cardiovascular disease: a populationbased cohort study. Int J Obes. 2006;30:1775-81. doi:10.1038/sj.ijo.0803339

50. Pons V, Riera J, Galilea PA, Drobnic F, Banquells M, Ruiz O. Características antropométricas, composición corporal y somatotipo por deportes. Datos de referencia del CAR de San Cugat, 1989-2013. Apunt Med l'Esport. 2015;50:65-72. doi:10.1016/j. apunts.2015.01.002 